\title{
Toxicological Evaluation of Thermoascus aurantiacus SI16W in Albino Rats: Subchronic Toxicity Study
}

\author{
${ }^{1}$ Watee Kongbuntad, ${ }^{3}$ Kanokporn Saenphet, ${ }^{1}$ Pairote Wongputtisin, \\ ${ }^{2}$ Chatchai Khanongnuch and ${ }^{3}$ Saisamorn Lumyong \\ ${ }^{1}$ Programe of Biotechnology, Faculty of Science, Maejo University, \\ 50290 Chiang Mai, Thailand \\ ${ }^{2}$ Department of Biotechnology, Faculty of Agro-Industry \\ ${ }^{3}$ Department of Biology, Faculty of Science, Chiang Mai University, \\ 50200 Chiang Mai, Thailand
}

\begin{abstract}
The purpose of this study was to evaluate the toxicology of crude xylanase enzymes prepared from T. aurantiacus SL16W in male Albino rats. Sixty rats aged 6 weeks old were randomly distributed into 4 groups of 15 rats. The 1st group was the untreated control while the 2 nd ( $400 \mathrm{U}), 3 \mathrm{rd}(2000 \mathrm{U})$ and 4 th (4000 U) groups received the crude xylanase enzyme at dose levels of 400,2000 and 4000 unit $/ \mathrm{kg}$ body weight/day, respectively. After treatmemt body weight, organ weight, hematology and plasma chemistry were examined. The results indicated that oral force-feeding of the crude xylanase enzyme did not affect the body and organ weight of the rats. Hemoglobin values in the $2000 \mathrm{U}$ group and hematocrit values in the $2000 \mathrm{U}$ group were slightly decreased compared to the control group. The levels of Blood Urea Nitrogen (BUN), creatinine, aspartate Aminotransferase (AST) and alanine Aminotransferase (ALP) were not significantly different between the groups except that the ALT of the $200 \mathrm{U}$ was significantly lower than the control group.
\end{abstract}

Key words: Thermoascus aurantiacus, xylanase, subchronic toxicity, toxicity test, enzyme, Thailand

\section{INTRODUCTION}

Thermorascus aurantiacus is a highly thermophilic fungus which produces enzymes such as xylanases and endoglucanases (Heldt-Hansen, 1997) cellulases and hemicellulases (Ryu and Mandels, 1980; Mandels, 1985; Beguin and Aubert, 1994; Bhat and Bhat, 1997) and endo-mannanase (Bar and Lindley, 1994). These enzymes are commonly used in many industrial applications (Bhat, 2000). T. aurantiacus is also known to produce cellulolytic and xylanolytic enzymes (Kalogeris et al., 2003). Various agriculture substrates-byproducts have been used successfully in Solid State Culture (SSC) for cellulase production from this fungus (Kalogeris et al., 1998; Fujian et al., 2002). In this study, researchers used T. aurantiacus SL16W isolated from soil samples from the Chiang Mai province, Thailand by Assoc. Saisamon Lumyong, Department of Biology, Faculty of Science, Chiang Mai University, Thailand. Optimum activity was achieved at high temperatures $\left(45-50^{\circ} \mathrm{C}\right)$ and low $\mathrm{pH}(\mathrm{pH} 5)$ in SSC. T. aurantiacus SL16W is also believed to be essential in improving the nutritive quality of animals feed. However, the toxicological effects in animals of crude enzyme prepared from T. aurantiacus SL16W has not been hitherto studied. Therefore, researchers studied the toxicological effects of the crude enzyme on the body weight, organ weight, hematology and blood chemistry of the albino rat. The objective of this study was to evaluate the toxicity of the crude enzyme which may be used to improve the nutrient efficiency in animals food in the future.

\section{MATERIALS AND METHODS}

Animals, housing and diets: Male Wistar stain rats, 6 weeks old and weighting $230 \pm 10 \mathrm{~g}$ were obtained from the breeding colony of the National Laboratory Animal Center. These rats were kept in a Strict Hygienic Conventional system. During the 1 st week of the acclimation period, each rat was housed individually in a barrier room in stainless-steel wire-mesh cages $37 \mathrm{~cm}$ long, $23 \mathrm{~cm}$ wide and $21 \mathrm{~cm}$ high. Animals were maintained in standard conditions including adequate ventilation an ambient temperature at $25 \pm 2^{\circ} \mathrm{C}$ and a relative humidity of

Corresponding Author: Watee Kongbuntad, Programe of Biotechnology, Faculty of Science, Maejo University, 50290 Chiang Mai, Thailand 
$60 \pm 15 \%$ with a $12 \mathrm{~h}$ light-dark cycle controlled via an automatic timer. The animals received commercial laboratory animal food pellets (Chalernpokkapun Co., Ltd., No. 082) and acidified filtered water $a d \mathrm{lib}$. The animals used in this study were kept in accordance with all applicable animal welfare regulations.

Solid State Culture (SSC) and crude enzyme preparation: T. aurantiacus SL16W gram were kept on PDA at $4^{\circ} \mathrm{C}$. Dried corncobs were prepared from corncobs boiled for $30 \mathrm{~min}$ for three run to obtain the sugar from a hot air oven process at $80^{\circ} \mathrm{C}$ until a constant dry weight was achieved. The corn was then milled in a hammer mill and passed through a $0.7 \mathrm{~mm}$ mesh-sized sieve before being used as a carbon source. The soybean meal was prepared with the same methods as an organic nitrogen source. Ammonium phosphate was used as the inorganic nitrogen source. The food component concentrations were calculated to provide $0.06 \mathrm{~g}$ Nitrogen per gram of corncob as was previously reported by Kasin-ubon. A SSC was carried out using a $250 \mathrm{~mL}$ Erlenmeyer flask containing a carbon source mixture of $1.7 \mathrm{~g}$ corncobs and $1.3 \mathrm{~g}$ soybean meal. Ammonium phosphate was dissolved with $5.5 \mathrm{~mL}$ of distilled water which was then added to the flask and mixed. The SSC was autoclaved for $40 \mathrm{~min}$ at $121^{\circ} \mathrm{C}$ and cooled at room temperature. Each flask was inoculated with three pieces $\left(0.5 \mathrm{~cm}^{2}\right)$ of 7 days old mycelia disk and incubated at $50^{\circ} \mathrm{C}$ for 7 days. The crude enzyme was extracted using $50 \mathrm{~mL}$ of cooled distilled water, mixed and kept at a temperature of $4^{\circ} \mathrm{C}$ for $60 \mathrm{~min}$. The solid materials and fungal biomass were separated by filtration through a cotton sheet and centrifuged at $1500 \mathrm{rpm}$ for $20 \mathrm{~min}$ at $4^{\circ} \mathrm{C}$. The supernatant was used as a crude enzyme solution. This method was carried out according to the Kasin-Ubon's procedure.

Experimental design and procedures: A Complete Randomized Design (CRD) was used for the experimental design. Animals were randomly distributed into 4 groups of 15 rats each. Animals were caged individually in stainless-steel wire-mesh cages. The 1 st group was untreated while the 2 nd, 3 rd and 4 th groups received the crude enzyme produced by T. aurantiacus SL16W at dose levels of 400,2000 and $4000 \mathrm{U} / \mathrm{kg}$ body weight/day, respectively (using the activity of xylanase). The crude enzyme samples were fed by oral force-feeding with a feeding needle 3 times a day at $8.00,12.00$ and 16.00 for 60 days. Food pellets and water were given $a d l i b$. The animals were weighed and three rats/group were randomly killed by cervical dislocation. An autopsy was done to determine the toxicity effect at the beginning of the experiment (on day 0 ) and on day 15,30,45 and 60, respectively. Blood samples were collected from a cardiac puncture with EDTA-2K anticoagulant tubes for the haematological examination and in the blood tubes for plasma chemistry. Haematological parameters included hemoglobin, haematocrit, white blood cell count and differential leukocyte count of the animals were determined by an Automatic Hematology Analyzer. Plasma chemistry parameters included Blood Urea Nitrogen (BUN), creatinine, aspartate Aminotransferase (AST), alanine aminotransferase (ALT) and Alkaline Phosphatase (ALP) were determined by automatic analyzer. A necropsy was carried out after the collection of blood samples. Dead animals were necropsied immediately after their discovery, all organs and tissues were subjected to gross examination to determine the toxicity effect of the crude enzyme.

The following organs; heart, liver, lung, spleen, kidneys and adrenal glands were rapidly removed and weighted. The relative organ weights ( $\mathrm{g} / \%$ body weight) were also calculated. Throughout the experiment, all animals were measured daily for food consumption and body weight.

Statistical analysis: The results were analyzed using an ANOVA procedure of the Statistical Analysis System Institute (SAS user's guide version 6.12, NC, USA). The level of significance was taken as $\mathrm{p}<0.05$.

\section{RESULTS AND DISCUSSION}

Body weights: Body weights were compared between the control and treated groups. There were different levels of crude enzyme (400, 2000 and 4000 unit $/ \mathrm{kg}$ body weight/day) throughout the study periods as shown in Fig. 1. The body weights in all groups similarly increased during the 5-45 days of the study periods with no

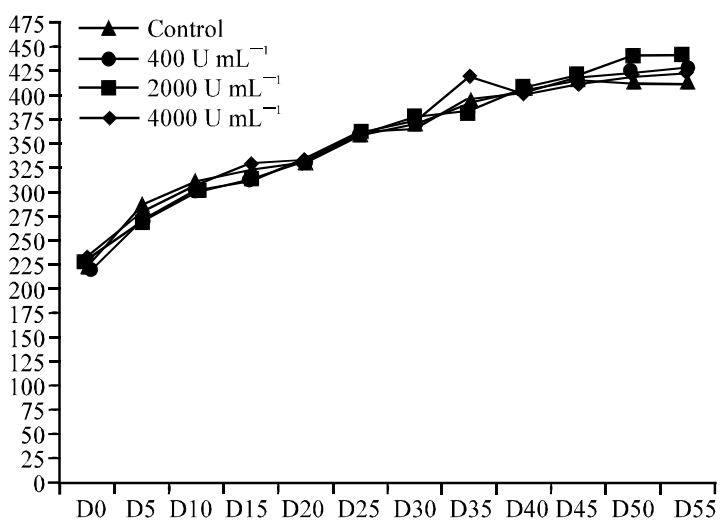

Fig. 1: Body weight of rats receiving crude enzyme for 60 days 
significantly differences between the groups. However, the body weight in the treated groups was slightly greater than in the control group during the last periods, although the different was not found to be statistically significant. Furthermore, the feed intake and feed efficiency ratio were comparable between the control and treated groups which no significant differences. As the results demonstrate, there was no toxicity effect that changed the body weight.

Organ weight: After 60 days of oral administration, the organs were rapidly removed for a weight determination. The studied organs were the heart, liver, lung, spleen, kidneys and adrenal glands. The relative organ weights ( $\mathrm{g} / \%$ body weight) were calculated and the results are shown in Table 1. The liver, heart, kidneys, spleen and kidney weights were not significantly different between treated and the control group. The lung weight of treated groups compared with the control group was found to be significantly greater in the 400 and $2000 \mathrm{U}$ groups than in the control group. However as all of the other results demonstrate, there were no abnormal signs in the organs and their weight changes. These results suggest that the oral force-feeding of crude enzyme was not toxic to the body weights and organs weight of male albino rats.

Haematological and plasma chemistry: Blood samples of the rats were collected at $0,15,30,45$ and 60 days. Hematological parameters such as hemoglobin concentration, hemaotocrit, total and differential leucocytes count were examined for comparison between control and treated groups. No significant differences were found at $0,15,30$ and 45 days. The hematological results at 60 days were significantly different as shown in Table 2. Hemoglobin values in the $4000 \mathrm{U}$ group and hematocrit values in the $2000 \mathrm{U}$ group were slightly decreased compared with the control group but it was not significantly different in $4000 \mathrm{U}$ group while in the $2000 \mathrm{U}$ group was significantly different. The results of total leucocytes values show a significantly increased in the treated groups compared with the control group. Furthermore, the leucocytes count such as eosinophil, neutrophil and basophil were not significantly different in all groups while the monocyte count in the $4000 \mathrm{U}$ group was significantly different compared with the control group. However, lymphocytes were found in the 400 and 2000 U groups only. Plasma chemistry parameters such as BUN, creatinine, AST, ALT and ALP were examined and compared between control group and treated groups as shown in Table 3. The level of BUN, creatinine, AST and ALP were not significantly different while the level of ALT in the $400 \mathrm{U}$ group showed a significant decrease when compared with the control group.
Table 1: Organs weight of rats which received crude enzymes for 60 days Organ weights $(\mathrm{g})$ mean $\pm \mathrm{SD}$

\begin{tabular}{|c|c|c|c|c|}
\hline \multirow{2}{*}{$\begin{array}{l}\text { Parameter of } \\
\text { organ weights } \\
(\mathrm{g} / \% \mathrm{LW})\end{array}$} & \multicolumn{4}{|c|}{ Dose of crude enzyme (Unit/kg body weight/day) } \\
\hline & 0 & 400 & 2000 & 4000 \\
\hline Liver & $3.43 \pm 0.20$ & $3.39 \pm 0.23$ & $3.10 \pm 0.04$ & $3.27 \pm 0.31$ \\
\hline Heart & $0.29 \pm 0.00$ & $0.27 \pm 0.02$ & $0.27 \pm 0.03$ & $0.30 \pm 0.04$ \\
\hline Lung & $0.40 \pm 0.02^{c}$ & $0.49 \pm 0.02^{\mathrm{a}}$ & $0.42 \pm 0.04^{\mathrm{cb}}$ & $0.46 \pm 0.01^{\mathrm{ab}}$ \\
\hline Kidneys & $0.51 \pm 0.03$ & $0.54 \pm 0.04$ & $0.54 \pm 0.03$ & $0.55 \pm 0.04$ \\
\hline Spleen & $0.19 \pm 0.01$ & $0.19 \pm 0.02$ & $0.18 \pm 0.01$ & $0.22 \pm 0.04$ \\
\hline Adrenal glands & $0.01 \pm 0.00$ & $0.02 \pm 0.00$ & $0.02 \pm 0.00$ & $0.02 \pm 0.00$ \\
\hline
\end{tabular}

LW: Life body weight. In each row, different letter differ significantly $\mathrm{p}<0.05$

Table 2: Hematology of rats receiving crude enzymes for 60 days Hematology (mean \pm SD)

Dose of crude enzyme (Unit/kg body weight/day)

\begin{tabular}{lllll}
$\begin{array}{l}\text { Parameters of } \\
\text { hematology }\end{array}$ & \multicolumn{1}{c}{0} & \multicolumn{1}{c}{400} & \multicolumn{1}{c}{2000} & \multicolumn{1}{c}{4000} \\
\hline $\begin{array}{l}\text { Hemoglobin } \\
\text { (mg dL }{ }^{-1} \text { ) }\end{array}$ & $15.50 \pm 0.62^{\mathrm{ab}}$ & $15.36 \pm 0.51^{\mathrm{ab}}$ & $16.10 \pm 0.40^{\mathrm{a}}$ & $14.83 \pm 0.68^{\mathrm{b}}$ \\
Hematocrit (\%) & $49.33 \pm 0.57^{\mathrm{a}}$ & $47.33 \pm 1.15^{\mathrm{ab}}$ & $46.33 \pm 1.15^{\mathrm{b}}$ & $47.33 \pm 2.30^{\mathrm{ab}}$ \\
Total leucocytes & $3.53 \pm 1.61^{\mathrm{a}}$ & $3.00 \pm 1.56^{\mathrm{a}}$ & $1.96 \pm 1.33^{\mathrm{ab}}$ & $4.00 \pm 1.05^{\mathrm{b}}$ \\
(cu/mm) $\times 10^{3}$ & & & & \\
Eosinophil & $11.33 \pm 0$ & $6.33 \pm 2.30$ & $5.33 \pm 4.16$ & $14.33 \pm 1.15$ \\
Neutrophil & $0.66 \pm 0.57$ & $2.00 \pm 1.73$ & $1.33 \pm 2.30$ & $1.66 \pm 0.57$ \\
Basophil & $85.30 \pm 10.26$ & $89.00 \pm 1.73$ & $87.60 \pm 6.80$ & $83.00 \pm 1$ \\
Monocyte & $2.66 \pm 2.08^{\mathrm{ab}}$ & $2.33 \pm 2.08^{\mathrm{ab}}$ & $5.55 \pm 2.51^{\mathrm{a}}$ & $1.00 \pm 0.1^{\mathrm{b}}$ \\
Lymphocyte & 0 & 0.33 & 0.33 & 0 \\
\hline WBC: White Blood Cell. In each row, different letters differ significantly \\
p<0.05
\end{tabular}

Table 3: Plasma chemistry of rats receiving crude enzymes for 60 days Plasma chemistry (mean \pm S.D)

Dose of crude enzyme (Unit kg-1 body weight day ${ }^{-1}$ )

\begin{tabular}{|c|c|c|c|c|}
\hline$\underline{\text { Parameters }}$ & 0 & 400 & 2000 & 4000 \\
\hline$\overline{\mathrm{BUN}}$ & $31.0 \pm 4.58$ & $27.0 \pm 5.29$ & $27.33 \pm 3.78$ & $30.33 \pm 1.52$ \\
\hline Creatinine & $0.83 \pm 0.11$ & $0.66 \pm 0.05$ & $0.76 \pm 0.05$ & $0.73 \pm 0.10$ \\
\hline AST & $176 \pm 46.48$ & $114.66 \pm 23.45$ & $149 \pm 26.05$ & $132.33 \pm 40.01$ \\
\hline ALT & $49.66 \pm 13.61^{a}$ & $34.0 \pm 1^{\mathrm{b}}$ & $52.66 \pm 2.08^{a}$ & $44.33 \pm 4.72^{\mathrm{ab}}$ \\
\hline ALP & $207 \pm 7.54$ & $174.0 \pm 45.13$ & $287.33 \pm 99.6$ & $186.66 \pm 39.57$ \\
\hline
\end{tabular}

BUN: Blood Urea Nitrogen, AST: Aspartate Aminotransferase, ALT: Alanine Aminotransferase, ALP: Alkaline Pphosphatase. In each row different letter differ significantly $\mathrm{p}<0.05$

\section{CONCLUSION}

The results demonstrate that the crude xylanase enzyme prepared from T. aurantiacus SL16W shows no toxicity on the body weight, organ weight, haematology and plasma chemistry in male albino rats when they are administered orally for 60 days.

\section{ACKNOWLEDGEMENTS}

Funds for this study were provided by the Graduated School of Chiang Mai University, Chiang Mai, Thailand and Mahasarakham University, Mahasarakham, Thailand.

\section{REFERENCES}

Bar, A. and M. Lindley, 1994. Nutitional and foodtechnological functions of partially depolymerised guaram. Int. Food Ingr., 6: 39-42. 
Beguin, P. and J.P. Aubert, 1994. The biological degradation of cellulose. FEMS Microbiol. Rev., 13: $25-58$.

Bhat, M.K. and S. Bhat, 1997. Cellulose degrading enzymes and their potential industrial applications. Biotechnol. Adv., 15: 583-620.

Bhat, M.K., 2000. Cellulases and related enzymes in biotechnology. Biotechnol. Adv., 18: 355-383.

Fujian, X., C. Hongzhang and L. Zuohu, 2002. Effect of periodically dyanamic changes of air on cellulase production in solid state fermentation. Enzyme Microbial. Technol., 30: 45-48.

Heldt-Hansen, H.P., 1997. Development of Enzymes for Food Applications. In: Biotechnology in the Food Chain-new Tools and Applications for Future Foods. Helsenki, Finland: VTT symp, Poutanen, K., (Edr.). Technical Research Centre of Finland, Finland, ISBN: 9789513845681, Pages: 260.
Kalogeris, E., P. Christakopoulos, D. Kekos and B.J. Macris, 1998. Studies on the solid-state production of thermostable endoxylanases from Thermoascus aurantiacus: Characterization of two isozymes. J. Biotechnol., 60: 155-163.

Kalogeris, E., P. Christakopoulos, P. Katapodis, A. Alexiou and S. Vlachou et al., 2003. Production and characterization of cellulolytic enzyme from the thermophilic fungus Thermoascus aurantiacus under solid state cultivation of agricultural wastes. Proc. Biochem., 38: 1099-1104.

Mandels, M., 1985. Applications of cellulases. Biochem. Soc. Trans., 13: 414-415.

Ryu, D.D. and M. Mandels, 1980. Cellulases: Biosynthesis and applications. Enzyme. Microbial. Technol., 2: $91-102$. 